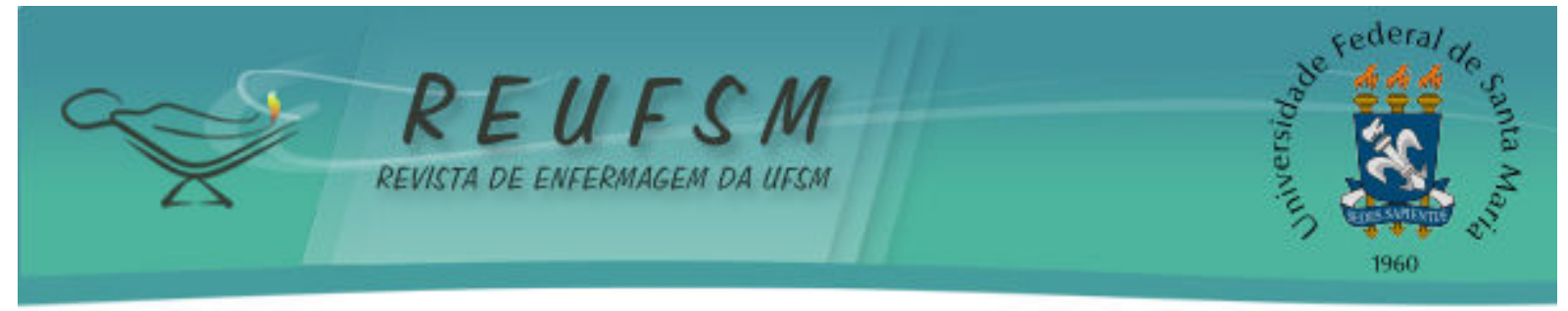

ARTIGO ORIGINAL

\title{
PERFIL SOCIODEMOGRÁFICO E EPIDEMIOLÓGICO DA VIOLÊNCIA SEXUAL CONTRA AS MULHERES EM TERESINA/PIAUÍ
}

\section{SOCIO-DEMOGRAPHIC AND EPIDEMIOLOGICAL PROFILE OF SEXUAL VIOLENCE AGAINST WOMEN IN TERESINAIPIAUÍ}

\section{PERFIL SOCIODEMOGRÁFICO Y EPIDEMIOLÓGICO DE LA VIOLENCIA SEXUAL CONTRA LAS MUJERES EN TERESINAIPIAUI}

\author{
Rosângela Pereira de Araujo ${ }^{1}$ \\ Fabrícia Miranda da Silva Sousa, Enfermeira² \\ Verbênia Cipriano Feitosa ${ }^{3}$ \\ Danieli Maria Matias Coêlho ${ }^{4}$ \\ Maria de Fátima Almeida e Sousa ${ }^{5}$
}

Doi: $10.5902 / 2179769214519$

RESUMO: A violência sexual constitui uma violação dos direitos humanos, se revelando como um problema de saúde pública. Objetivo: caracterizar as mulheres vítimas de violência sexual quanto aos aspectos sociodemográficos e epidemiológicos. Método: estudo retrospectivo quantitativo, realizado no Serviço de Atenção às Mulheres Vítimas de Violência Sexual no Piauí. Foram investigados 74 prontuários com diagnóstico de violência sexual entre 2013 a 2014. Utilizou-se o software Statistical Package for the Social Science, versão 20.0 para calcular as estatísticas descritivas apropriadas às variáveis da pesquisa. Resultados: o estudo mostrou prevalência na faixa etária entre 18 e 27 anos, a maioria de cor parda e com ensino fundamental, predominando mulheres solteiras e de baixa renda. Conclusão: os resultados apontam que a violência sexual tem várias facetas, indistingue etnia, classe social e idade requerendo, assim, o planejamento de ações mais resolutivas e complexas no âmbito social e da saúde.

Descritores: Perfil epidemiológico; Saúde da mulher; Violência sexual; Violência doméstica.

ABSTRACT: Sexual violence is considered a violation of human rights, becoming a public health problem. Objective: to characterize women victims of sexual violence according to socio-demographic and epidemiological aspects. Method: quantitative retrospective study conducted in the Department of Care of Women Victims of Sexual Violence, in Piauí. The study investigated 74 records of diagnosis of sexual violence between 2013 and 2014. The Statistical Package for Social Sciences software, version 20.0, was used to calculate the

\footnotetext{
${ }^{1}$ Enfermeira. Bacharel em Enfermagem pelo Centro de Ensino Unificado de Teresina- CEUT. TeresinaPiauí/Brasil. tratosecabelos@hotmail.com.

${ }^{2}$ Bacharel em Enfermagem pelo Centro de Ensino Unificado de Teresina- CEUT. Teresina-Piauí/Brasil. fabricyamiranda@hotmail.com.

${ }^{3}$ Enfermeira. Mestre em Enfermagem pela Universidade federal do Piauí. Docente do curso Bacharel em Enfermagem do Centro de Ensino Unificado de Teresina- CEUT. Teresina-Piauí/Brasil. verbeniafeitosa@gmail.com.

${ }^{4}$ Enfermeira. Mestre em Ciências e Saúde pela Universidade Federal do Piauí. Docente do curso Bacharel em Enfermagem do Centro de Ensino Unificado de Teresina - CEUT. Teresina-Piauí/Brasil. danielibrisa@hotmail.com.

${ }^{5}$ Enfermeira. Especialista em Saúde Pública pela Faculdade de Ribeirão Preto. Docente do curso Bacharel em Enfermagem do Centro de Ensino Unificado de Teresina - CEUT. Teresina-Piauí/Brasil. enfa_fatima@hotmail.com.
} 


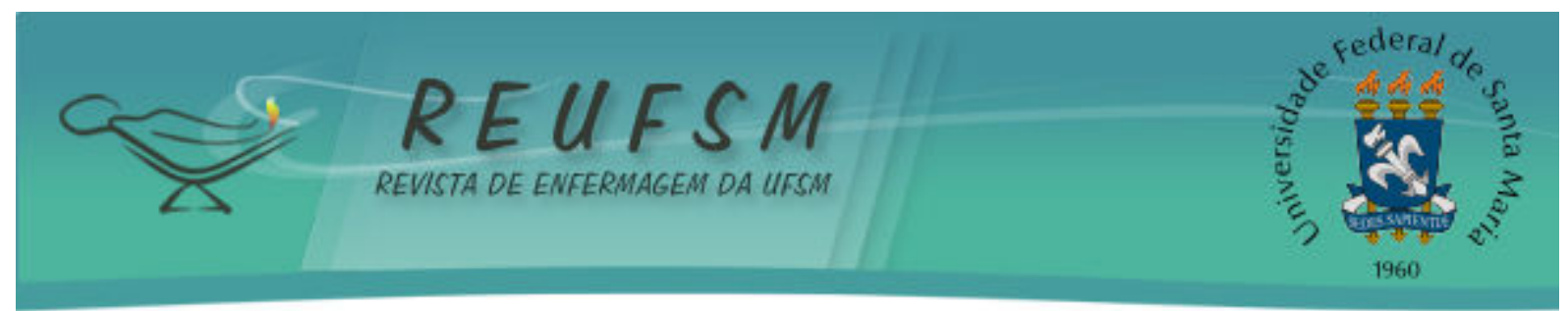

descriptive statistics appropriate to the variables of the study. Results: the study showed prevalence in the age group between 18 and 27 years old, most of them were pardo and had completed elementary school, predominantly single and with low-income. Conclusion: the results indicate that sexual violence has several facets, not distinguishing ethnicity, social class or age, and requiring, thus, the planning of more complex and effective actions in the health and social context.

Descriptors: Epidemiology profile; Women's health; Sexual violence; Domestic violence.

RESUMEN: La violencia sexual constituye una violación de los derechos humanos, revelándose como un problema de salud pública. Objetivo: caracterizar mujeres víctimas de violencia sexual en aspectos sociodemográficos y epidemiológicos. Método: estudio retrospectivo cuantitativo, realizado en el Servicio de Atención a Mujeres Víctimas de Violencia Sexual en Piauí (Brasil). Se investigaron 74 informes con ese diagnostico entre 2013 y 2014. Fue utilizado el software Statistical Package for the Social Science, versión 20.0 calculando estadísticas descriptivas apropiadas al estudio. Resultados: el estudio mostró prevalencia de edad entre 18 y 27 años, la mayoría pardas con enseñanza fundamental, predominando mujeres solteras con bajos ingresos. Conclusión: los resultados apuntan que la violencia sexual contra las mujeres tiene varias facetas, no distingue etnia, clase social o edad y requiere la planificación de acciones más efectivas y complejas en el ámbito social y de salud.

Descriptores: Perfil epidemiológico; Salud de la mujer; Violencia sexual; Violencia doméstica.

\section{INTRODUÇÃO}

A violência é um tema abrangente e bastante discutido em todo o mundo, em função de suas consequências na qualidade de vida do indivíduo e da coletividade. Quando se discute sobre violência contra as mulheres, este problema torna-se ainda mais preocupante pelo fato de que estas, em sua maioria, representam o elo de fortalecimento dos laços familiares.

Dentre as violências praticadas contra as mulheres, destaca-se, neste estudo, a violência sexual, por constituir-se como um grave problema de saúde pública no Brasil, sendo um dos agravos à saúde da mulher de maior relevância e incidência nos últimos anos, provocando forte impacto nos aspectos físicos, sociais e psicológicos das vítimas. A mulher que vivencia a violência sexual sofre profundas alterações no seu cotidiano, o que pode, em alguns casos, torná-la prisioneira do silêncio resultante da vergonha de expor sua condição de violênciax. ${ }^{1}$

A violência sexual configura-se como toda ação na qual uma pessoa, em situação de poder, obriga outra a realizar prática sexual contra a vontade, por meio de força física, influência psicológica, uso de armas ou drogas, independente de sua relação com a vítima. ${ }^{2}$ Nesse contexto, a violência sexual é uma grave violação dos direitos humanos e acontece de forma global, resultante de uma cultura que prevalece a discriminação social, econômica, de gênero e raça, na qual o homem exerce papel de poder em relação à mulher. ${ }^{3}$

Sob o aspecto jurídico, a expressão mais grave da violência sexual é o estupro, cujo significado é expresso como a prática da conjunção carnal ou qualquer ato libidinoso, mediante grave ameaça ou violência física. Anteriormente, somente a mulher podia ser vítima de estupro, e só seria configurado crime mediante conjunção carnal, ou seja, mediante a penetração do pênis na vagina. Forçar qualquer outro tipo de penetração (penetração anal) não caracterizava estupro, mas sim crime de atentado violento ao pudor. Seguindo a atual orientação constitucional e o que dita os Princípios dos Direitos Humanos Sexuais e Reprodutivos, o que antes era considerado crime contra os costumes 


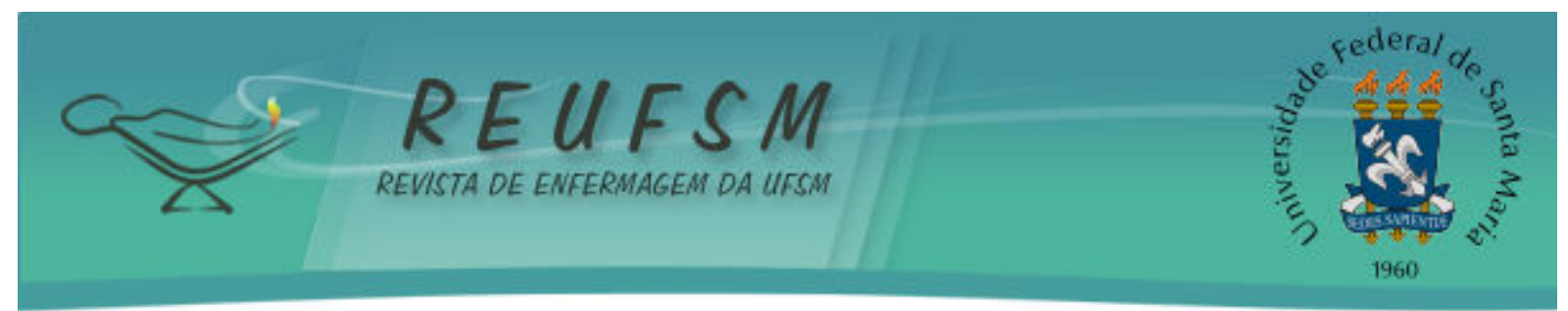

morais, configura-se hoje crime contra a dignidade sexual. Portanto, os crimes estupro, violação sexual, assédio sexual e crimes contra vulnerável são considerados, de uma forma ampla, violência sexual. ${ }^{3}$

Com a criação em 2004 da Política Nacional de Atenção Integral à Saúde da Mulher (PNAISM) pelo Ministério da Saúde e em parceria com diversos movimento sociais, dentre eles, os de mulheres, o âmbito da saúde avança na garantia dos direitos humanos da mulher, cujo objetivo geral é implementar ações de saúde visando a redução da morbimortalidade por causas preveníveis e evitáveis, e, dentre os objetivos específicos, promover a atenção às mulheres e adolescentes em situação de violência doméstica e sexual. ${ }^{4}$

Para o enfrentamento da violência contra as mulheres vale destacar em âmbito nacional, marcos políticos e jurídicos de suma importância, como a criação do Pacto Nacional pelo Enfrentamento à Violência Contra a Mulher, lançado em agosto de 2007, que consiste em um acordo entre todas as esferas do governo: Federal, Estadual e Municipal. Visa, por meio de implementação de políticas públicas integradas, assegurar ações como a aplicabilidade da Lei Maria da Penha, ampliação e fortalecimento da rede de serviços para mulheres em situação de violência, garantindo a segurança cidadã, acesso à Justiça, direitos sexuais e reprodutivos, enfrentamento à exploração sexual e ao tráfico de mulheres, autonomia das mulheres em situação de violência e ampliação de seus direitos. ${ }^{5-6}$

Dentre estes, se destaca a Lei Maria da Penha de $n^{\circ} 11.340 / 2006$, que cria mecanismos para coibir e prevenir a violência doméstica e familiar contra as mulheres, nos termos do $\S 8^{\circ}$ do art. 226 da Constituição Federal; tem-se ainda a Convenção sobre a Eliminação de Todas as Formas de Violência contra as Mulheres; a Convenção Interamericana para Prevenir, Punir e Erradicar a Violência contra as Mulheres e outros tratados internacionais ratificados pela República Federativa do Brasil..,

Frente ao exposto, este estudo tem como questão norteadora: qual o perfil sociodemográfico e epidemiológico das mulheres em situação de violência sexual atendidas pelo Serviço de Atenção às Mulheres Vítimas de Violência Sexual (SAMVVIS) de Teresina/PI? O objetivo é caracterizar as mulheres vítimas de violência sexual quanto aos aspectos sociodemográficos e epidemiológicos.

A relevância desse estudo consiste na possibilidade do real conhecimento da situação de violência sexual que atinge as mulheres, na perspectiva de desvendar os fenômenos que as envolvem, subsidiando a criação de políticas e ações mais efetivas no âmbito social e da saúde e proporcionar aos profissionais de saúde maior conhecimento dos aspectos que envolvem a violência sexual contra as mulheres, possibilitando um atendimento mais humanizado, direcionado e qualificado.

\section{MÉTODO}

A pesquisa configurou-se como um estudo do tipo análise documental, retrospectivo, de abordagem quantitativa. A população de referência da pesquisa constituiu-se por todas as mulheres que foram atendidas no SAMVVIS, no período de 2012 a 2013. O critério de inclusão foi mulheres com diagnóstico confirmado de violência sexual e idade igual ou superior a 18 anos. Quanto ao tamanho da amostra, o total foi calculado pela técnica de amostragem Aleatória Simples Sem Reposição (AASS). Adotando um intervalo de $95 \%\left(z_{\alpha}=1,96\right)$ de confiança nas estimativas e levando em consideração as mulheres vítimas de violência sexual em 2012 e 2013 em Teresina-Piauí, totalizando 554 vítimas. Considerando um erro amostral (B) de $5 \%$ nos parâmetros a serem estimados, o tamanho da amostra foi dado por: 


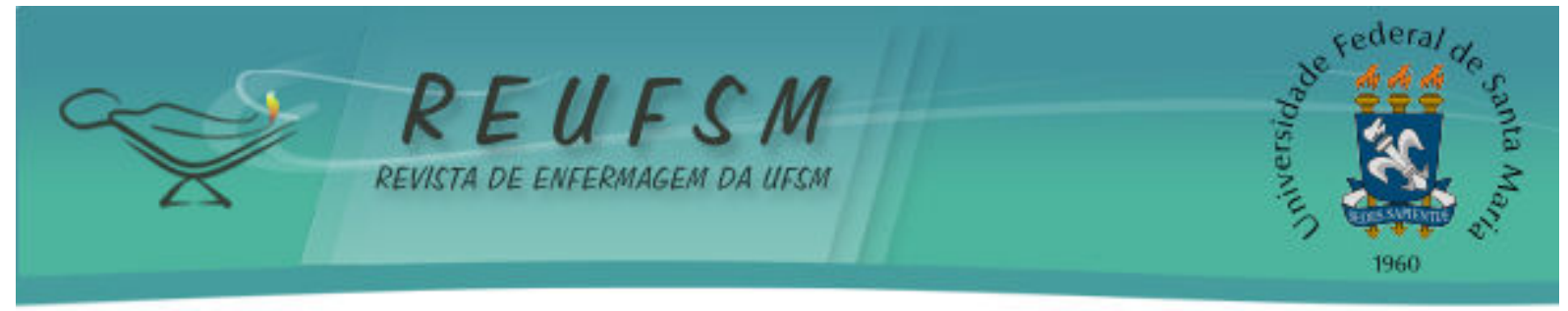

$$
D=\frac{B^{2}=0,0025}{\mathrm{z}_{\mathrm{a}}^{2}=3,8416}=0,00065 \quad n=\frac{1}{D=0,00065 / S^{2}=0,055+1 / N=554} \cong 74
$$

Desse modo, foram investigados 74 prontuários no SAMVVIS.

A coleta de dados ocorreu no mês de maio de 2014 após o projeto de pesquisa ser submetido ao Comitê de Ética em Pesquisa da Faculdade de saúde, ciências humanas e tecnológicas do Piauí- NOVAFAPI, sendo aprovado com parecer $\mathrm{N}^{\circ} 639.249$ (CAEE 26235314.6.0000.5210). Inicialmente, foi realizada a busca aleatória dos prontuários, a partir dos livros de registros e admissão das pacientes que deram entrada no SAMVVIS no período de janeiro de 2012 a dezembro de 2013. Antes de iniciar a busca dos dados nos prontuários, as pesquisadoras assinaram o Termo de Compromisso de Utilização de Dados (TCUD) no qual se comprometeram a manter a confidencialidade sobre os dados coletados nos arquivos (prontuários) do SAMVVIS, bem como a privacidade de seus conteúdos.

Por se tratar de estudo com utilização de base de dados secundários, não foi necessário solicitação de emissão de Termo de Consentimento Livre e Esclarecido, no entanto, foi solicitada a emissão de Termo de Autorização Institucional. Portanto, foram respeitados todos os preceitos éticos contidos na Resolução $466 / 12$ do Conselho Nacional de Saúde, que aprovam diretrizes e normas regulamentadoras de pesquisas envolvendo seres humanos.

Para sistematizar os dados foi utilizado um formulário-padrão com questões predominantemente fechadas, referentes às características epidemiológicas. Utilizou-se o software Statistical Package for the Social Science (SPSS), versão 20.0 o que permitiu calcular as estatísticas descritivas tais como frequência absoluta, relativa, média, e outras apropriadas às variáveis da pesquisa.

\section{RESULTADOS}

Conforme a Tabela 1, a média de idade foi de 33,2 anos com desvio padrão de 15,2 anos. Com um intervalo de confiança de 95\%, a verdadeira média ficou entre 29,7 e 36,7 anos. Tem-se que 50\% da amostra tem menos de 29 anos e 6 meses (mediana=29,5), com idade mínima e máxima de, respectivamente, 18 e 84 anos.

Tabela 1 - Estatísticas descritivas da idade das mulheres em situação de violência sexual atendidas no SAMVVIS. Teresina, $2014(\mathrm{~N}=74)$.

\begin{tabular}{llr}
\hline & & \multicolumn{1}{c}{ Estatística } \\
\hline & Média & 33,2 \\
Intervalo de confiança de 95\% para & 29,7 \\
Idade & média & 36,7 \\
& Mediana & Limite inferior \\
& Desvio padrão & 29,5 \\
& Mínimo & 15,2 \\
& Máximo & 18 \\
& & 84 \\
\hline
\end{tabular}

Fonte: Pesquisa direta 


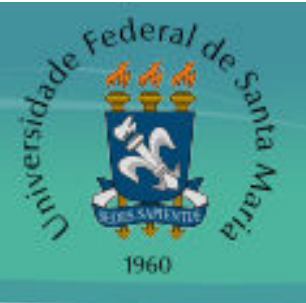

Na Figura 1 observa-se que a maior parte das mulheres em situação de violência está entre 18 e 40 anos. E acima de 60 anos a frequência é relativamente baixa.

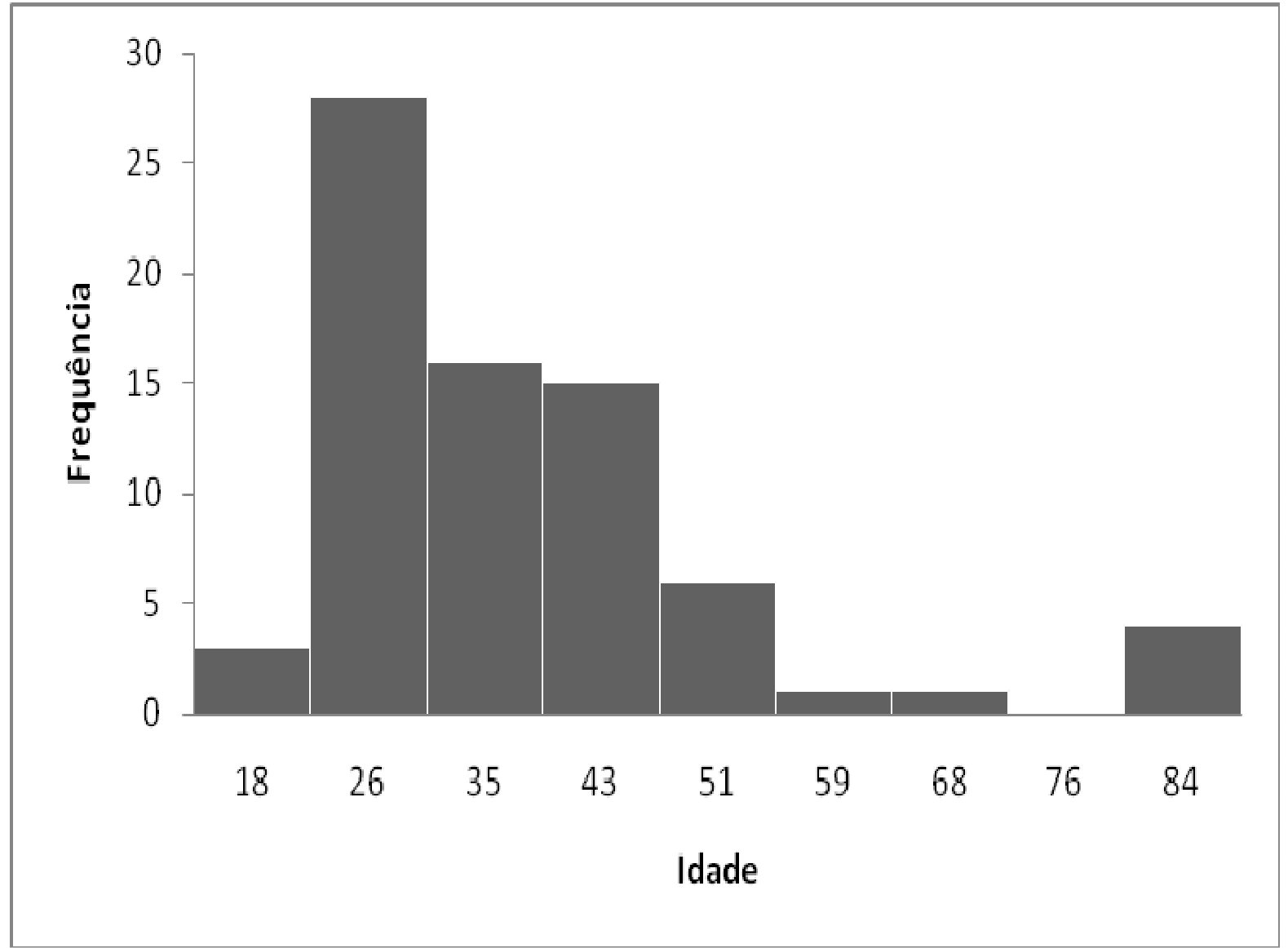

Figura 1 - Histograma da idade das mulheres em situação de violência atendidas no SAMVVIS. Teresina, $2014(\mathrm{~N}=74)$. 


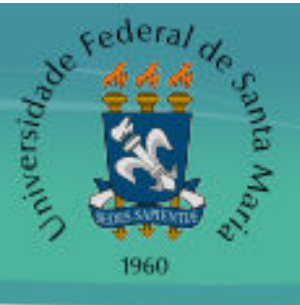

Tabela 2 - Caracterização socioeconômica e demográfica das mulheres em situação de violência sexual atendidas no SAMVVIS. Teresina, $2014(\mathrm{~N}=74)$.

\begin{tabular}{|c|c|c|}
\hline Variável & $\mathrm{N}$ & $\%$ \\
\hline \multicolumn{3}{|l|}{ Idade (anos) } \\
\hline 18 a 27 & 35 & 47,3 \\
\hline 28 a 37 & 18 & 24,3 \\
\hline $38 \mathrm{e}+$ & 21 & 28,4 \\
\hline \multicolumn{3}{|l|}{ Cor da pele } \\
\hline Branca & 16 & 21,6 \\
\hline Preta & 11 & 14,9 \\
\hline Parda & 38 & 51,3 \\
\hline Não identificado & 9 & 12,2 \\
\hline \multicolumn{3}{|l|}{ Local que reside } \\
\hline Teresina & 51 & 68,9 \\
\hline Interior do Piauí & 23 & 31,1 \\
\hline \multicolumn{3}{|l|}{ Nível de escolaridade } \\
\hline Analfabeto & 14 & 18,9 \\
\hline Fundamental & 25 & 33,8 \\
\hline Médio & 22 & 29,7 \\
\hline Superior & 12 & 16,2 \\
\hline Não identificado & 1 & 1,4 \\
\hline \multicolumn{3}{|l|}{ Situação conjugal } \\
\hline Casada/união estável & 13 & 17,6 \\
\hline Solteira & 57 & 77,0 \\
\hline Não identificado & 4 & 5,4 \\
\hline \multicolumn{3}{|l|}{ Renda mensal $(\mathrm{N}=59)$} \\
\hline 1 Salário mínimo & 37 & 62,6 \\
\hline 1 a 2 Salários mínimos & 9 & 15,3 \\
\hline >3 Salários & 3 & 5,1 \\
\hline Não identificado & 10 & 17,0 \\
\hline Total & 74 & 100 \\
\hline
\end{tabular}

Fonte: Pesquisa direta 


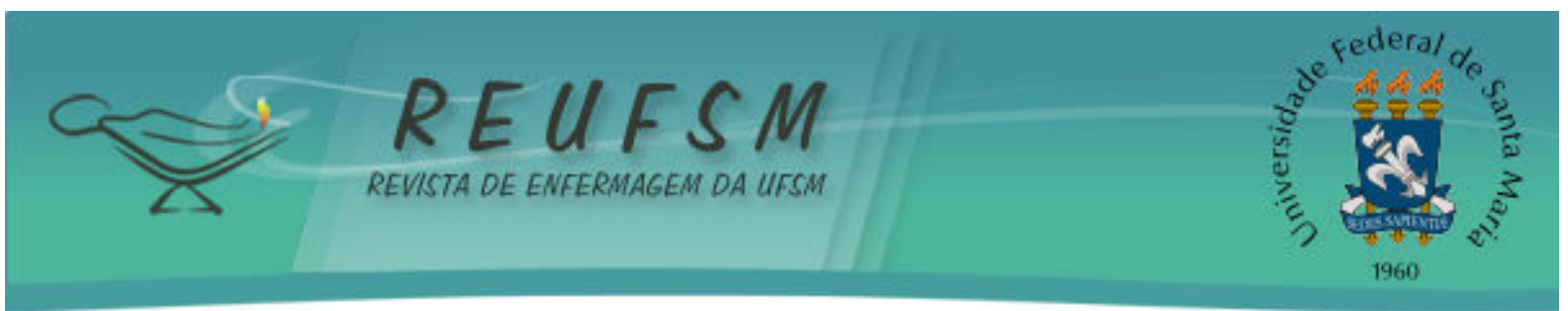

Tabela 3 - Distribuição das mulheres em situação de violência sexual atendidas no SAMVVIS, segundo os dados da história da violência. Teresina, $2014(\mathrm{~N}=74)$.

\begin{tabular}{lcc}
\hline \multicolumn{1}{c}{ Variável } & N & $\%$ \\
\hline Local de Violência & 26 & 35,1 \\
Residência das mulheres & 6 & 8,1 \\
Residência do agressor & 27 & 36,5 \\
Via Pública & 1 & 1,4 \\
Trabalho & 14 & 18,9 \\
Outros & & \\
Período de ocorrência & 28 & 37,8 \\
Diurno & 46 & 62,2 \\
Noturno & & \\
Agressor Conhecido & 45 & 60,8 \\
Sim & 29 & 39,2 \\
Não & & 94,5 \\
No de agressores & 70 & 4,1 \\
Um até dois & 3 & 1,4 \\
Acima de dois & 1 & \\
Não identificado & & 44,5 \\
Tipo de Intimidação & 33 & 31,1 \\
Força Física & 23 & 9,5 \\
Arma & 7 & 14,9 \\
Força Física e arma & 11 & 35,4 \\
Não identificado & & 100 \\
Tipo de substância tóxica & 22 & \\
Álcool & 26 & \\
Outras drogas & 26 & Álcool/Drogas \\
Total & 74 & \\
\hline Fonte: Pesquisa direta & \\
\hline & & \\
\hline
\end{tabular}

Fonte: Pesquisa direta

\section{DISCUSSÃO}

Em relação à análise dos aspectos epidemiológicos das mulheres em situação de violência sexual atendidas pelo SAMVVIS, este estudo evidenciou que a violência sexual atinge mulheres em diferentes fases do ciclo vital, desde a adolescência à velhice, cuja idade média foi de 29,7 anos, com mínima de 18 anos e máxima de 84 anos. Dados semelhantes foram encontrados em outro estudo, no qual a idade máxima foi de 85 anos, a mínima de 12 anos e a média de 23,7 anos. $^{7}$

0 estudo mostrou que houve predomínio da faixa etária entre 18 a 27 anos. Este resultado foi semelhante aos encontrados em um estudo com mulheres em situação de violência assistidas no pronto socorro/hospital de clínicas de Uberlândia ${ }^{8}$ e também com as mulheres em situação de violência atendidas em um serviço universitário de referência no Estado de São Paulo ${ }^{7}$, nos quais as mulheres tinham idades entre 18 a 30 anos. ${ }^{8-9}$ Este fato pode estar associado aos padrões de cultura do brasileiro, uma vez que nessa faixa etária a mulher se encontra no ápice de sua juventude e beleza, podendo despertar no homem 


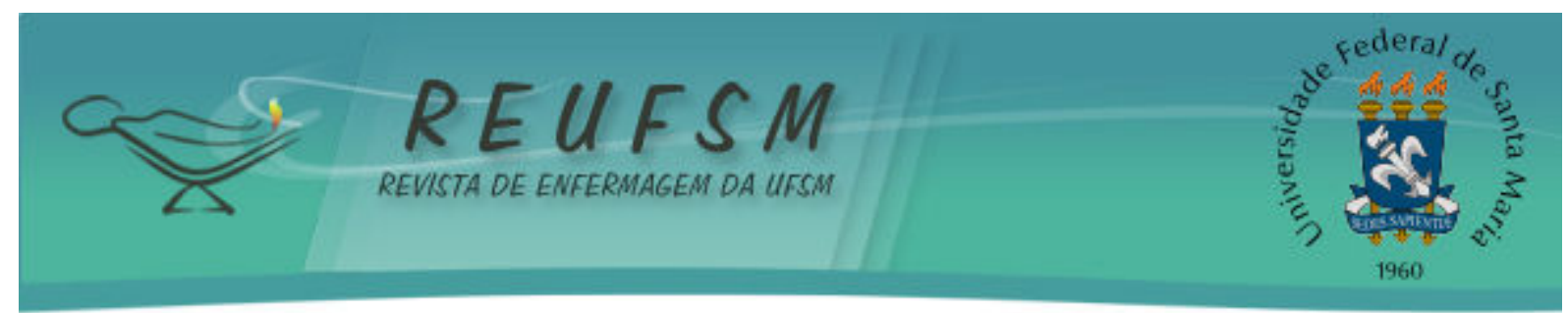

desejos, inseguranças, ciúmes e atos autoritários de violência,entretanto o fato da mulher ser nova e bonita não justifica tal comportamento por parte de alguns homens.

Em relação à cor, a maioria das mulheres declararam-se pardas, este dado foi contraditório ao encontrado em um estudo cujo objetivo era avaliar o perfil, características da agressão, sintomas psíquicos e seguimento ambulatorial de mulheres que procuravam atendimento no Centro de Atenção Integral à Saúde da Mulher em situação de violência sexual, no qual foi encontrado predomínio de mulheres brancas. ${ }^{9}$

Tais afirmativas justificam a premissa de que a violência sexual indistingue raça, classe social ou outro aspecto demográfico. Ou ainda consolidam uma mudança na distribuição ou recuperação da identidade racial no Brasil nas últimas décadas, que segundo os dados divulgados pelo setor de Pesquisa Nacional por Amostra de Domicílios (PNAD), realizada anualmente pelo Instituto Brasileiro de Geografia e Estatística (IBGE), há um significativo aumento da população que se declara negra ou parda..$^{10-12}$

Sobre a procedência das mulheres atendidas pelo SAMVVIS, grande parte residia na cidade de Teresina, enquanto que as demais residiam em outras cidades do interior do estado do Piauí. A implantação deste serviço em outros municípios do estado do Piauí possibilitou o acesso das mulheres em situação de violência sexual em seus respectivos municípios de domicílio, facilitando e ampliando a cobertura da assistência prestada a essas mulheres, desafogando o atendimento do SAMVVIS do município de Teresina, evitando o deslocamento da vítima para outros municípios.

Com base na Norma Operacional da Assistência à Saúde (NOAS-SUS), Portaria MS/GM, fevereiro de 2002, que trata da regionalização da assistência à saúde, capítulo I, o Estado tem o dever de garantir o acesso dos cidadãos, o mais próximo possível de sua residência, as ações e serviços cujas responsabilidades mínimas são, dentre outras, ações de promoção e prevenção de doenças, tratamento dos distúrbios mentais e psicossociais mais frequentes. ${ }^{13}$

No que diz respeito à escolaridade, a maioria das mulheres atendidas cursaram o ensino fundamental, contrastando com $16,2 \%$ que cursaram o ensino superior. 0 estudo sobre o perfil das mulheres em situação de violência no município de Taquara/RS, também verificou a predominância de mulheres que cursaram apenas o ensino fundamental $(62,7 \%) .{ }^{14}$ Por outro lado, dados sobre a situação da mulher no estado do Piauí revela que entre 2007 e 2012 houve um crescimento de $78 \%$ de mulheres cursando o ensino superior, e no mesmo período o percentual de mulheres com apenas o ensino fundamental foi de $5,85 \% .{ }^{15}$

Encontrou-se nessa pesquisa uma frequência elevada de mulheres solteiras contradizendo estudos pesquisados, nos quais as mulheres em situação de violência sexual se declaravam casadas $(60,2 \%) .{ }^{9}$ Este fato, provavelmente, deve ocorrer devido a uma característica nacional de muitos casais não oficializarem sua união, mas manterem um relacionamento estável, sem oficialização, se considerando casadas ao serem indagadas sobre sua situação conjugal.

Ao se investigar a renda das mulheres em situação de violência sexual atendidas pelo serviço, grande parte relatou renda de um salário mínimo. Dado semelhante foi encontrado no estudo "Repercussões psicoemocionais da violência doméstica: perfil de mulheres na atenção básica, realizada na cidade João Pessoa/PB", cujo índice foi de 72,0\% com renda de um salário mínimo. ${ }^{16}$

A pesquisa "violência contra a mulher: caracterização de casos atendidos em um centro estadual de referência de Fortaleza - CE com mulheres em situação de violência" trouxe também resultado semelhante, mostrando que $57,08 \%$ das mulheres ganhavam até três salários mínimos. ${ }^{17}$ Isso demonstra que a violência sexual incide, sobretudo, nas mulheres com baixa renda, o que pode estar ligado ao fato de que as dificuldades financeiras provocam desestruturação familiar e social, favorecendo comportamentos agressivos. 


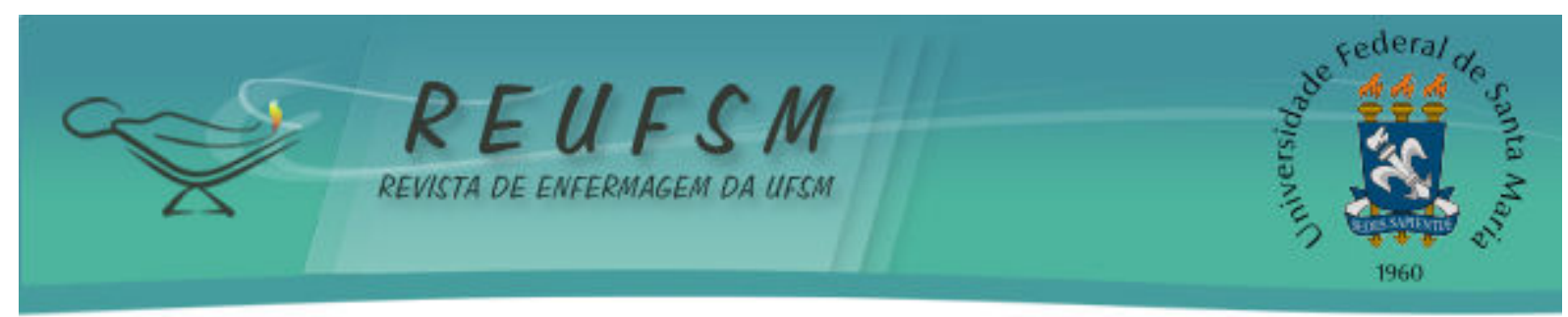

Entretanto, esta afirmação deve ser analisada com cautela, pois o fato da maior prevalência de violência acontecer nas classes sociais menos favorecidas não implica dizer que nas classes sociais mais abastadas a violência sexual não esteja presente. Pode ser devido à subnotificação, visto que elas preferem ocultar a violência sofrida, pois não querem dar visibilidade ao problema. ${ }^{16,18}$

Quanto à história da violência sexual destas mulheres, o estudo constatou percentuais muito próximos entre a ocorrência na própria residência das mulheres e em via pública. Um estudo sobre a "Caracterização da violência sexual em mulheres atendidas no projeto Maria-Maria em Teresina-PI" encontrou dados semelhantes a esta pesquisa, no qual $39,2 \%$ dos casos de violência ocorreram em local fora das residências das mulheres ou do agressor, $34,3 \%$ na própria residência das mulheres e $18,6 \%$ na residência do agressor. ${ }^{19}$ Enquanto o estudo sobre "Mulheres vítimas de violência sexual: adesão à quimioprofilaxia do HIV" relatou que a residência do agressor foi o local de preferência $(29,6 \%)$, seguido por $16,2 \%$ nas residência das mulheres e $13,4 \%$ no matagal, entre outros espaços públicos. ${ }^{20}$

Estes dados variam de acordo com o perfil da violência e do agressor. A agressão que ocorre em vias públicas, matagais ou lugares ermos, geralmente o agressor é desconhecido. A violência ocorrida na residência da vítima ou do agressor, tem como autor da violência, um agressor conhecido, cujo percentual foi elevado neste estudo e com laços afetivos com as mulheres, contrastando com valores de $16 \%$ e $9 \%$ aos encontrados por outros estudos. ${ }^{19-20}$

A violência ocorrida na própria residência das mulheres configura violência intradomiciliar, onde impera, baseado em algumas regras sociais que estão sendo quebradas ao longo das últimas décadas, o domínio e poder dos homens em relação às mulheres. Estas podem, ao se sentirem em posição inferior ao homem e por medo de perder a segurança familiar que o lar lhe proporciona, calar-se. Porém, situações opostas podem ocorrer, onde o agressor sendo conhecido e que inspira confiança as mulheres, levam-nas à lugares ermos e praticam o ato violento, ou agressores desconhecidos invadem as residências das mulheres para cometer atos ilícitos, juntamente com a violência sexual. ${ }^{19-20}$

$\mathrm{Na}$ maioria dos casos analisados neste estudo, a violência sexual ocorreu em horário noturno, dados semelhantes foram encontrados em vários outros estudos. Portanto deduz-se que esse horário foi propício para a perpetração do ato. ${ }^{7,19,21}$

Ao analisar as variáveis associadas aos números de agressores, constatou-se que predominou o número de um a dois agressores, confirmando achados prévios obtidos por outro pesquisador, no qual apontou que $83,4 \%$ dos casos de violência sexual contra as mulheres no município de Campina Grande-Paraíba foi perpetrada por agressor único. Em dois casos apenas, o estupro foi consumado por dois ou mais agressores. ${ }^{22} 0$ número de agressores envolvidos na violência sexual é um fator agravante nesse tipo situação, visto que alguns autores revelaram que as mulheres em situação de violência sexual desenvolvem sequelas psicológicas mais graves, quando o abuso sexual é realizado por múltiplos agressores.

Constatou-se, neste estudo, que a maioria dos agressores se valeu da força física para intimidar as mulheres. Resultado parecido foi encontrado em outro estudo, no qual $35,9 \%$ dos casos sofreram além da violência sexual, violência do gênero. ${ }^{23}$ Várias são as estratégias que podem ser adotadas pelo agressor para a prática de atos sexuais, entre as quais o uso ou a ameaça de uso da força física. Não obstante, os agressores utilizam estratégias mais sutis, que não implicam o uso da força física, como exemplo a pressão psicológica e/ou agressão verbal, que são apontados com frequiência como métodos utilizados para a consumação da violência sexual.

Quanto à presença de substâncias químicas consumidas pelo agressor, foram identificados, neste estudo, percentuais iguais de agressores que estavam sob o efeito de álcool e drogas quando praticaram a violência. Em relação ao uso de álcool, um percentual 


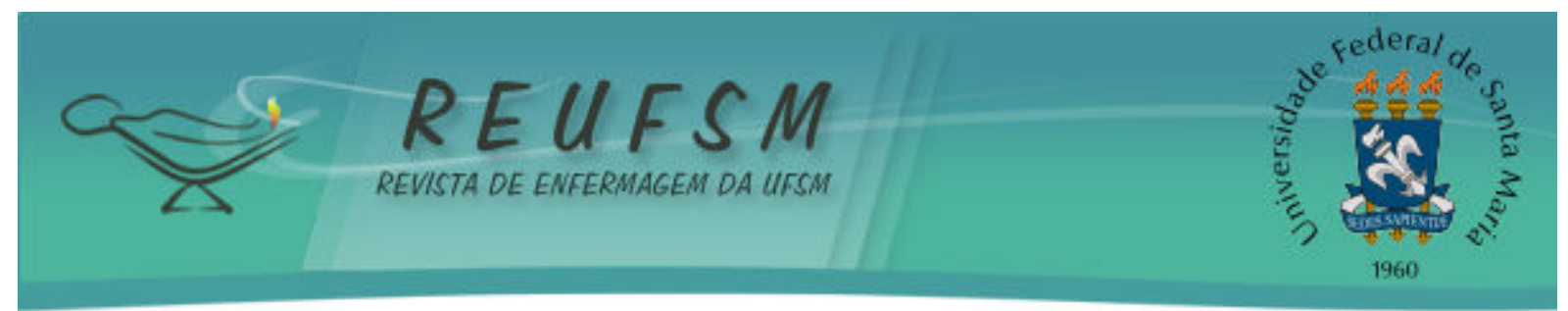

ainda maior foi encontrado por outro estudo, onde $82 \%$ dos agressores tinham consumindo bebidas alcoólicas antes de praticarem o ato violento. ${ }^{24}$

Diversos estudos apontam uma estreita ligação entre o consumo de álcool/drogas e o crime. O consumo abusivo de bebidas alcoólicas e outras substâncias psicoativas representam um risco para a perpetração de atos violentos, incluindo dirigir em alta velocidade, perturbar a ordem pública, homicídios, crimes sexuais e violência familiar, porém o crime é um fenômeno complexo e multifatorial e associá-lo unicamente ao uso nocivo de substâncias psicoativas é pouco sustentável. ${ }^{25}$

\section{CONCLUSÃO}

O presente estudo permitiu avaliar as características sociodemográficas e epidemiológicas da violência sexual contra as mulheres no estado Piauí. No que diz respeito aos fatores socioeconômicos e demográficos, o estudo mostrou que as mulheres pardas, idade entre 18 a 27 anos, com escolaridade baixa, solteiras e com renda de até um salário mínimo, são as mais afetadas pela violência sexual no estado do Piauí.

A maioria ocorreu na cidade de Teresina, principalmente em horário noturno, em locais diversos da residência das mulheres ou do agressor, e teve como autor um agressor conhecido, que sob o efeito de álcool e/ou outras drogas se utilizaram da força física para perpetrarem ato de violência sexual contra essas mulheres. Outro dado importante sobre o perfil das mulheres vítimas de violência sexual atendidas pelo SAMVVIS-PI, identificado pelo estudo, foi a alarmante maioria de adolescentes em situação de violência sexual, 0 que demanda novos estudos sobre esta questão.

Embora tenha havido uma considerável conscientização nos âmbitos social e da saúde em relação à assistência às mulheres em situação de violência sexual, este estudo evidenciou uma urgência na efetivação de políticas e programas de combate e tratamento às mulheres em situação de violência, bem como a articulação desses setores, a fim de compor um sistema único e integralizado, resultando numa assistência holística e resolutiva.

No tocante a área de saúde percebeu-se que os profissionais de saúde, principalmente os enfermeiros, muitas vezes se deparam com problemas de cunho social, e nem sempre estão preparados para enfrentá-los. Intencionou-se com este estudo, revelar os aspectos epidemiológicos e socidemográficos de mulheres em situação de violência sexual, valorizando-os na tomada de decisões e assim proporcionar um atendimento acolhedor e humanizado, pois se faz necessário que os atores que compõem este cenário de atendimento e tratamento adotem posturas de escuta atenciosa, segura e sem préjulgamentos nesse momento de fragilidade existencial.

\section{REFERÊNCIAS}

1. Departamento Intersindical de Estatística e Estudos Socioeconômicos (DIEESE). Anuário das mulheres brasileiras. DIEESE; 2011.

2. Organização Mundial de Saúde (OMS). Violência contra la mujer [Internet]. 2012 [acesso em 2013 out 22]. Disponível em: http://www.who.int/mediacentre/factsheets/fs239/es/. (Nota descriptiva; 239).

3. Brasil. Lei $n^{\circ} 12.015$, de 07 de agosto de 2009. Altera o Título VI da Parte Especial do Decreto-Lei $n^{\circ} 2.848$, de 07 de dezembro de 1940 - Código Penal, e o art. $1^{\circ}$ da Lei $n^{\circ}$ 8.072, de 25 de julho de 1990, que dispõe sobre os crimes hediondos, nos termos do inciso 


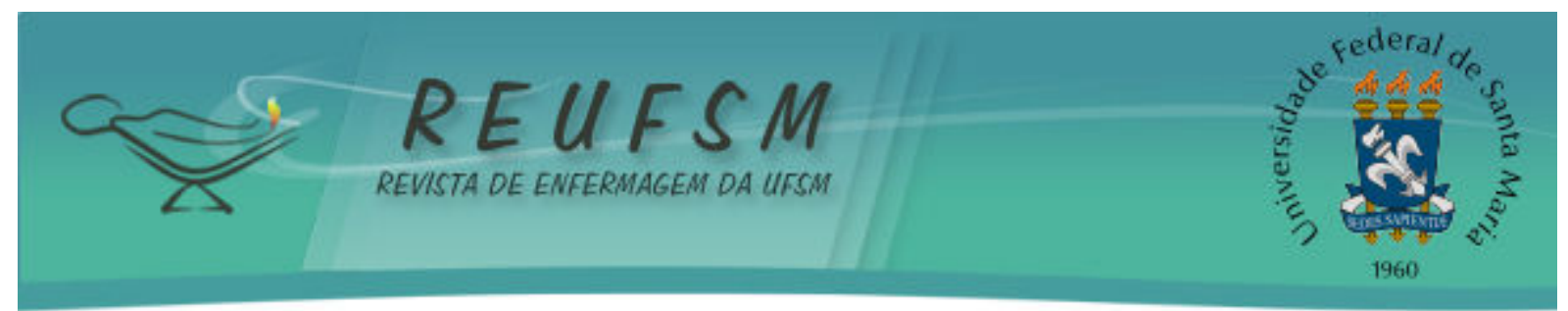

XLIII do art. $5^{\circ}$ da Constituição Federal e revoga a Lei $n^{\circ} 2.252$, de $1^{\circ}$ de julho de 1954 , que trata de corrupção de menores. Diário Oficial da União, Brasília; 2009 ago 10.

4. Brasil. Secretária de Atenção à Saúde. Política Nacional de Atenção Integral à Saúde da Mulher. Brasília(DF); 2004.

5. Brasil. Secretária de Políticas para as Mulheres. Pacto nacional pelo enfrentamento à violência contra a mulher. Brasília(DF); 2011.

6. Poll MA, Weiller TH, Mayer BLD, Borges TAP, Silva KF, Baumgart D. Caracterização das mulheres agredidas em uma zona de fronteiras urbana localizada em região de fronteiras. Rev Enferm UFSM [Internet]. 2013 mar [acesso em 2014 maio 25];3(N Esp):658-67 Disponível em:

2.2.2/index.php/reufsm/article/view/11042. http://cascavel.ufsm.br/revistas/ojs-

7. Facuri CO, Fernandes AMS, Oliveira KD, Andrade TS, Azevedo RCS. Violência sexual: estudo descritivo sobre as vítimas e o atendimento em um serviço universitário de referência no estado de São Paulo. Cad Saúde Pública. 2013;29(5):889-98.

8. Andrade MF, Giuliani CD, Biffi EFA. Perfil de mulheres vítimas de violência assistidas no pronto socorro/Hospital das Clínicas - UFU. Rev Fatos \& Versões. 2011;3(5):103-33.

9. Ribeiro DKL, Duarte JM, Lino KC, Fonseca MRCC. Caracterização das mulheres que sofrem violência doméstica na cidade de São Paulo. Rev Saúde Coletiva. 2009;6(35):264-8.

10. Facuri CO. Caracterização sociodemográficas e sintomas psíquicos de mulheres vítimas de violência sexual [dissertação]. Campinas: UNICAMP; 2012.

11. Marques $Y C B$, Santos CRN. Análise da humanização do acolhimento da equipe de enfermagem à mulher vítima de violência sexual. Id Online Rev Piscológia [Internet]. 2011 nov [acesso em 2014 maio 22];5(15):57-65. Disponível em: http://idonline.emnuvens.com.br/id/article/view/22.

12. Instituto Brasileiro de Geografia e Estatística (IBGE). Censo do Piauí - 2010. Teresina (PI): IBGE; 2010.

13. Brasil. Ministério da Saúde. Portaria $n^{\circ} 373$, de 27 de fevereiro de 2002. Aprova a Norma Operacional da Assistência à Saúde - NOAS-SUS 01/2002 que amplia as responsabilidades dos municípios na Atenção Básica e estabelece o processo de regionalização como estratégia de hierarquização dos serviços de saúde e de busca de maior eqüidade. Diário Oficial da República Federativa Brasil. 2002 fev 28; Seção 1.

14. Berz DSS, Coiro SDP. Violência contra a mulher: perfil da mulher vítima de violência doméstica no município de Taquara/RS [monografia]. Taquara: Faculdades Integradas de Taquara; 2013.

15. Fundação Centro de Pesquisas Econômicas e Sociais do Piauí - CEPRO. Sobre a situação da mulher no estado do Piauí [Internet]. Teresina (PI): CEPRO; 2014 [acesso em 2014 maio 29]. Disponível em: http://www.cepro.pi.gov.br/acervo.php.

16. Vale SLL, Medeiros CMR, Cavalcanti CO, Junqueira CCS, Sousa LC. Repercussões psicoemocionais da violência doméstica: perfil de mulheres na atenção básica. Rev RENE. 2013;14(4):683-93.

17. Costa AM, Moreira KAP, Henriques ACPT, Marques JF, Fernandes AFC. Violência contra a mulher: caracterização de casos atendidos em um centro estadual de referencia. Rev RENE. 2011;12(3):627-35. 


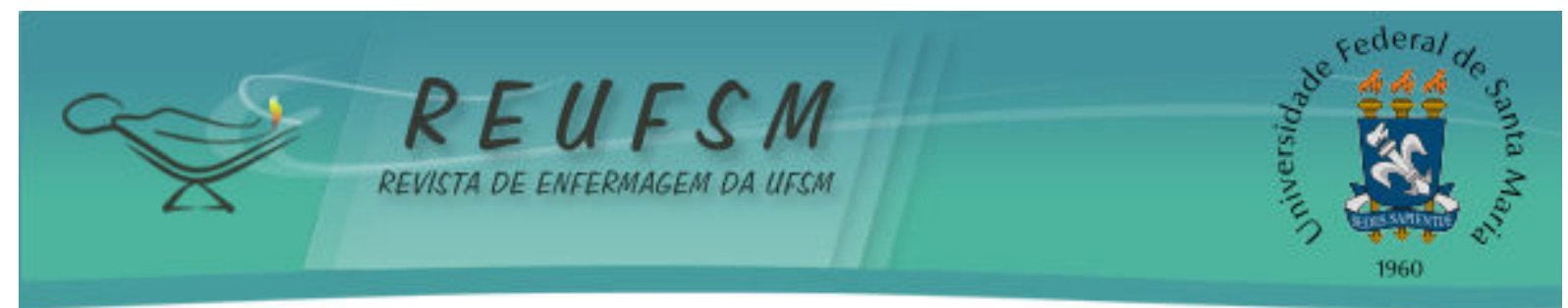

18. Instituto de Pesquisa Econômica Aplicada (IPEA). Políticas sociais: acompanhamento e análise. Brasília: IPEA; 2011.

19. Lopes IMRS, Gomes KRO, Silva BB, Deus MCBR, Galvão ERCGN, Borba DC. Caracterização da violência sexual em mulheres atendidas no projeto Maria-Maria em Teresina-PI. Rev Bras Gin Obstetrícia. 2004;26(2):111-6.

20. Diniz NMF, Almeida LCG, Ribeiro BCS, Macêdo VG. Mulheres vítimas de violência sexual: adesão à quimioprofilaxia do HIV. Rev Latinoam Enferm. 2007;15(1):7-12.

21. Oliveira PM, Carvalho MLO. Perfil das mulheres atendidas no programa municipal de atendimento à mulher vítima de violência sexual em Londrina/PR e as circunstâncias da violência sexual sofrida: período de outubro de 2011 a agosto de 2004. Semina: Ciên Biol Saúde. 2006;27(1):3-11.

22. Souto RQ, Silva AFR, Oliveira RC, Cavalcanti AL. Violência sexual contra a mulher no município de Campina Grande, Paraíba. Rev Bras Pesq Saúde. 2010;12(3): 30-8.

23. Garcia MV, Ribeiro LA, Jorge MT, Pereira GR, Resende AP. Caracterização dos casos de violência contra a mulher atendidos em três serviços na cidade de Uberlândia, Minas Gerais. Cad Saúde Pública. 2008;24(11):2551-63.

24. Araujo MAL, Andrade RFV, Cavalcante CS, Pereira KMC. Violência de gênero em mulheres com diagnóstico de doenças sexualmente transmissíveis no nordeste do Brasil. Rev Baia Saúde Pública. 2012;36(3):713-26.

25. Cortez FCP, Baltieri AD. A violência e o consumo nocivo de álcool. Rev Criminol Ciên Penitenciárias [Internet]. 2011 [acesso em 2014 maio 10];1(2):[SI]. Disponível em: http://www.procrim.org/revista/index.php/COPEN/article/view/26.

Data de recebimento: $25 / 06 / 2014$

Data de aceite: $11 / 12 / 2014$

Contato com autor responsável: Rosângela Pereira de Araujo

Endereço postal: Rua 19 de novembro, 1238 Bairro Porenquanto Teresina-Piauí.

E-mail: tratosecabelos@hotmail.com 